\title{
STUDI KASUS MIOPIA ASTIGMATIS TERHADAP PENGLIHATAN BACA DEKAT PADA MAHASISWA OPTOMETRI STIKES DHARMA HUSADA BANDUNG
}

\author{
Nuraisah $^{1)}$, Muhamad Randi Prawira ${ }^{2)}$ \\ ${ }^{1,2)}$ Program Studi Diploma Tiga Refraksi Optisi STIKes Dharma Husada \\ ${ }^{1)}$ nuraisah479@gmail.com \\ ${ }^{2)}$ prawirarandiw@gmail.com
}

\begin{abstract}
Abstrak
Miopia merupakan kelainan refraksi yang insidensinya di beberapa rumah sakit Indonesia berkisar antara 50\% sampai 80,3\%. Prevalensi miopia pada mahasiswa kedokteran dua kali lebih tinggi daripada populasi biasa dilingkungan yang sama. Faktor resiko yang berhubungan dengan kejadian miopia adalah genetik dan lama aktivitas baca dekat. Menggambarkan Miopia Astigmatis terhadap penglihatan dekat pada Mahasiswa Optometri STIKes Dharma Husada Bandung 2020, dan juga ingin melihat jarak baca pada yg masih berusia usia muda. Dalam penelitian ini peneliti menggunakan metode pengumpulan data, yaitu deskriptif diantaranya dengan menggunakan Lembar observasi, hasil pemeriksaan refraksi, yang dapat langsung digunakan untuk analisa hasil di saat yang bersamaan (point time Approach). Didapati hasil 5 orang yang diperiksa ada 2 orang yang mengalami kelainan akomodasi, dikarenakan hasilnya tidak sesuai dengan revalansi dioptri amplitudo akomodasi.
\end{abstract}

Kata kunci : lag accommodation,raf rule, bailey lovie, akomodasi

\section{PENDAHULUAN}

Kelainan refraksi mata merupakan gangguan mata, dimana mata tidak dapat melihat/ fokus dengan jelas pada suatu area terbuka sehingga pandangan menjadi kabur dan untuk kasus yang parah, gangguan ini dapat menjadikan visual impairment (melemahnya penglihatan). Kelainan refraksi yang umum terjadi antara lain myopia (rabun jauh), hipermetropia (rabun dekat), dan astigmatisme. presbiopia kadang juga dimasukkan ke dalam golongan kelainan refraksi mata. (Lukman, Lindra, \& Heriana, 2016).

Di Indonesia, prevalensi kebutaan dan gangguan penglihatan akibat kelainan refraksi mencapai $22,1 \%$ dari total populasi, $15 \%$ diantaranya diderita oleh anak usia sekolah.
Prevalensi severe lowvision (visus mata terbaik $<6 / 60$ - 3/60) pada usia produktif (15-54 tahun) sebesar 1,49\% dan prevalensi kebutaan (visus mata terbaik <3/60) sebesar 0,5\%. Prevalensi severe low vision dan kebutaan meningkat pesat pada penduduk kelompok usia 45 tahun keatas dengan rata-rata peningkatan sekitar 2-3 kali lipat setiap 10 tahun. Prevalensi severe low vision dan kebutaan tertinggi ditemukan pada kelompok usia 75 tahun keatas sesuai peningkatan proses degeneratif padausia tua. (Rifati L, 2013).

Saat ini, sekitar 314 juta orang di dunia mengalami penglihatan lemah dan 45 juta diantaranya merupakan kasus kebutaan. Insiden penglihatan lemah di negara berkembang sebesar $87 \%$ dan sepertiganya terjadi di Asia Tenggara. Hasil Riset Kesehatan 
Dasar tahun 2013 menunjukkan data gangguan penglihatan karena katarak sebesar 1.8\% dan severe low vison sebesar $0.9 \%$, sedangkan yang menggunakan kaca mata 4.6\%. Hasil

Survei Kebutaan Rapid Assessment of Avoidable Blindness atau RAAB tahun 20142016 di 15 provinsi menunjukkan penyebab utama gangguan penglihatan dan kebutaan adalah kelainan refraksi $10-15 \%$ dan katarak 70-80\%. (Dinas Kesehatan Jawa Barat dr.H.Dodo Suhendar, 2017).

Miopia merupakan kelainan refraksi yang insidensinya di beberapa rumah sakit Indonesia berkisar antara $50 \%$ sampai $80,3 \%$. Salah satu faktor risiko yang berhubungan dengan kejadian miopia adalah genetik dan lama aktivitas jarak dekat. (ARIANTI, 2013).

Hasil suatu penelitian diketahui prevalensi astigmat $\geq 0,5 \mathrm{D}$ pada populasi normal sebesar $73,53 \%$; astigmat $\geq 1,0 \mathrm{D}$ sebesar $32,78 \%$; astigmat $\geq 1,5 \mathrm{D}$ sebesar $13,55 \%$; dan astigmat $\geq 2,0$ D sebesar $6,86 \%$. Penelitian tersebut menunjukan bahwa Astigmat with the rule didapatkan pada 53,3\% dari populasi; against the rule pada $28,3 \%$ dari populasi dan $18,4 \%$ dari populasi merupakan oblique astigmatism. (Nemeth G, 2013).

Penelitian ini meneliti kelainan refraksi miopia astigmatis compocitus terhadap penglihatan dekat pada mahasiswa Optometri STIKes Dharma Husada untuk mengetahui apakah yang mengalami kelainan miopia astigmatis compocitus berpengaruh terhadap penglihatan baca dekat nya.

\section{METODE PENELITIAN}

Metode penelitian adalah deskriftif yaitu menggambarkan kelainan refraksi di STIKes Dharma Husada Bandung dengan indicator kelainan refraksi myopia astigmatis, power tertinggi antara myopia astigmatism, kelainan refraksi menurut usia, kelainan refraksi menurut jenis kelamin. Pendekatan waktu penelitian secara cross sectional, yaitu dengan cara pengumpulan data tentang indikator kelainan refraksi miopia astigmatis, higga mendapatkan data kelainan miopia astigmatis. (point time Approach). Penelitian dilaksanakan di kampus dan di laboratoruim Refraksi STIKes Dharma Husada Bandung

Karakteristik subjek penelitian mencakup pasien yang mengalami kelainan refraksi yang berada di lingkungan STIKes Dharma Husada Bandung dalam 1 bulan. Sampel penelitian adalah mahasiswa yang mengalami kelainan refraksi miopia astigmatis compucitus di program studi Optometri STIKes Dharma Husada Bandung berjumlah 5 orang.

Instrumen yang digunakan dalam penelitian adalah trial lens set untuk melakukan pemeriksaan kelainan refraksi, lembar observasi yang berisi nama, jenis kelamin, usia, ukuran kacamata lama, visus dasar, visus setelah dikoreksi, ukuran hasil koreksi mata kanan dan kiri, raf rule dan bailey lovie diagnosa. Dalam penelitian ini peneliti menggunakan metode pengumpulan data, yaitu deskriptif diantaranya dengan menggunakan Lembar observasi, hasil pemeriksaan refraksi, yang dapat langsung 
digunakan untuk analisa hasil di saat yang bersamaan (point time Approach).

Pengumpulan data dilaksanakan bulan Februari 2020, dilakukan dengan cara melakukan pemeriksaan langsung jarak baca dengan menggunakan koreksi maksimal / aidded dan tanpa koreksi / unaidded dan menggunnakan alat Bailey Lovie dan raf rule pada responden dan dilakukan secara monokuler. Pemeriksaan untuk penilaian test baca dekat dilakukan pemeriksaan refraksi untuk jarak jauhnya dulu dengan koreksi yang terbaik dan dilakukan secara monokuler mata kanan, kemudian mata kiri. Kemudian pemeriksaan untuk jarak baca dekatnya dilakukan secara binokuler, dimana test baca dekatnya dengan menggunakan alat raf rule dan bailey lovie, dengan mencari lag akomodasi pada pasien dengan hasil jarak yang berbeda-beda.

Pengolahan data dengan cara analisis univariat yaitu analisis yang digunakan pada satu variabel Kelainan refraksi responden dibedakan dalam kategori 1) Ringan dan 2) Sedang

\section{HASIL DAN PEMBAHASAN}

\section{A. HASIL}

Tabel 1 Distribusi berdasarkan jarak baca dekat nya

\begin{tabular}{|c|c|c|c|c|c|}
\hline \multirow{2}{*}{ No } & \multirow{2}{*}{ Koreksi } & \multirow{2}{*}{$\begin{array}{c}\text { Jenis } \\
\text { Kelamin }\end{array}$} & \multirow{2}{*}{ Usia } & \multicolumn{2}{|c|}{ RAF Rule } \\
\hline & & & & Aided & Unaided \\
\hline \multirow[t]{5}{*}{1} & OD : & Laki laki & 20 & $25 \mathrm{~cm}(\mathrm{~N} 5)$ & $24 \mathrm{~cm}(\mathrm{~N} 5)$ \\
\hline & $\mathrm{S}-1.25$ & & & $24 \mathrm{~cm}(\mathrm{~N} 5)$ & $23 \mathrm{~cm}(\mathrm{~N} 5)$ \\
\hline & C- 0.25 X60 & & & $24 \mathrm{~cm}(\mathrm{~N} 5)$ & $24 \mathrm{~cm}(\mathrm{~N} 5)$ \\
\hline & OS : & & & & \\
\hline & S- -0.25 & & & & \\
\hline \multirow[t]{5}{*}{2} & OD : & Perempuan & 20 & $32 \mathrm{~cm}(\mathrm{~N} 5)$ & $28 \mathrm{~cm}(\mathrm{~N} 5)$ \\
\hline & S-0.50 & & & $37 \mathrm{~cm}(\mathrm{~N} 5)$ & $27 \mathrm{~cm}(\mathrm{~N} 5)$ \\
\hline & $\mathrm{C}-0.25 \times 65$ & & & $34 \mathrm{~cm}(\mathrm{~N} 5)$ & $28 \mathrm{~cm}(\mathrm{~N} 5)$ \\
\hline & OS : & & & & \\
\hline & S- -0.25 & & & & \\
\hline \multirow[t]{6}{*}{3} & OD: & Laki-laki & 21 & $26 \mathrm{~cm}(\mathrm{~N} 5)$ & $17 \mathrm{~cm}(\mathrm{~N} 5)$ \\
\hline & S-1.25 & & & $27 \mathrm{~cm}(\mathrm{~N} 5)$ & $17 \mathrm{~cm}(\mathrm{~N} 5)$ \\
\hline & C- 0.75 X180 & & & $30 \mathrm{~cm}(\mathrm{~N} 5)$ & $18 \mathrm{~cm}(\mathrm{~N} 5)$ \\
\hline & OS: & & & & \\
\hline & S-0.50 & & & & \\
\hline & C- $0.75 X 180$ & & & & \\
\hline \multirow[t]{6}{*}{4} & OD: & Perempuan & 21 & $26 \mathrm{~cm}(\mathrm{~N} 5)$ & $24 \mathrm{~cm}(\mathrm{~N} 5)$ \\
\hline & S-1.25 & & & $30 \mathrm{~cm}(\mathrm{~N} 5)$ & $24 \mathrm{~cm}(\mathrm{~N} 5)$ \\
\hline & C- $0.75 \times 60$ & & & $29 \mathrm{~cm}(\mathrm{~N} 5)$ & $24 \mathrm{~cm}(\mathrm{~N} 5)$ \\
\hline & OS: & & & & \\
\hline & S-0.75 & & & & \\
\hline & C- $0.75 \times 80$ & & & & \\
\hline \multirow[t]{6}{*}{5} & OD: & Laki-laki & 22 & $44 \mathrm{~cm}(\mathrm{~N} 5)$ & $20 \mathrm{~cm}(\mathrm{~N} 5)$ \\
\hline & S-5.00 & & & $46 \mathrm{~cm}(\mathrm{~N} 5)$ & $20 \mathrm{~cm}(\mathrm{~N} 5)$ \\
\hline & C- $0.25 \times 90$ & & & $45 \mathrm{~cm}(\mathrm{~N} 5)$ & $20 \mathrm{~cm}(\mathrm{~N} 5)$ \\
\hline & OS: & & & & \\
\hline & S-4.00 & & & & \\
\hline & C- $0.25 \times 90$ & & & & \\
\hline
\end{tabular}


Gambaran kelainan refraksi miopia astigmatis compocitus terhadap baca dekat berdasarkan usia dan jenis kelamin. Dengan rata-rata usia remaja yang berumur 20 tahun, dan juga yang berjenis kelamin laki-laki berjumlah 3 orang, 2 diantaranya berakomodasi dengan normal, dan yang berjenis kelamin perempuan berjumlah 2 orang, 1 diantaranya berakomodasi dengan normal.

Tabel 2 Distribusi berdasarkan rata-rata jarak baca dekat

\begin{tabular}{ccccc}
\hline No & Nama & Raf Rule (aided) & D & Bailey Lovie(aided) \\
\hline 1 & Omar & $24,33 \mathrm{~cm}$ (rata-rata) & $1,27 \mathrm{D}$ & $25,67 \mathrm{~cm}$ rata-rata \\
\hline 2 & Dede & $34,33 \mathrm{~cm}$ (rata-rata) & $1,84 \mathrm{D}$ & $36 \mathrm{~cm}$ rata-rata \\
\hline 3 & Abraham & $27,67 \mathrm{~cm}$ (rata-rata) & $1,49 \mathrm{D}$ & $22 \mathrm{~cm}$ rata-rata \\
\hline 4 & Thalia & $28,33 \mathrm{~cm}$ (rata-rata) & $1,54 \mathrm{D}$ & $30 \mathrm{~cm}$ rata-rata \\
\hline 5 & Dicky & $45 \mathrm{~cm}$ (rata-rata) & $2,22 \mathrm{D}$ & $30 \mathrm{~cm}$ rata-rata \\
\hline
\end{tabular}

Kelainan refraksi miopia astigmatis compocitus terhadap baca dekat berdasarkan jarak baca adalah 28,66 cm dengan derajat miopia ringan, dan $45 \mathrm{~cm}$ dengan derajat miopia sedang

\section{Tabel 3 Distribusi Rata-rata Amplitudo Akomodasi}

\begin{tabular}{lc}
\hline Kelompok Miopia & $\begin{array}{c}\text { Amplitudo Akomodasi } \\
\text { (D) }\end{array}$ \\
\hline Ringan (4) & Rata-rata 1,89 \\
\hline Sedang (1) & Rata-rata 2,78 \\
\hline
\end{tabular}

Kelanain miopia astigmatis compocitus terhadap baca berdasarkan derajat amplitudo akomodasi adalah 1,89 derajat miopia ringan dan 2,78 derajat miopia sedang.

\section{B. PEMBAHSAN}

Berdasarkan tabel 4.1 diatas diketahui bahwa hasil tes baca dekat dengan menggunakan raf rule, dari tiga kali percobaan tes baca dekat, sampel pertama berjenis kelamin laki-laki yang berusia 20 tahun dengan power koreksi maksimal (aided) mata kanan S1,25 C- 0,25 X 60 dan power mata kiri S- 1,75 menghasilkan 3 hasil jarak baca dekat sebesar
$25 \mathrm{~cm}, 24 \mathrm{~cm}, 24 \mathrm{~cm}, \quad$ dan jika tidak menggunakan koreksi maksimal atau (unaided) menghasilkan 3 hasil jarak baca dekat sebesar $24 \mathrm{~cm}, 23 \mathrm{~cm}, 24 \mathrm{~cm}$. Sampel kedua berjenis kelamin perempuan yang berusia 20 tahun dengan power koreksi maksimal (aided) mata kanan S- 0.50 C- 1,00 X 65 dan power mata kiri S- 0.25 menghasilkan 3 hasil jarak baca dekat sebesar $32 \mathrm{~cm}, 37 \mathrm{~cm}, 34 \mathrm{~cm}$. Dan jika tidak menggunakan koreksi maksimal atau (unaided) menghasilkan 3 hasil jarak baca dekat sebesar $28 \mathrm{~cm}, 27 \mathrm{~cm}, 28 \mathrm{~cm}$. Sampel ketiga berjenis kelamin laki-laki yang berusia 21 tahun dengan power koreksi maksimal (aided) mata kanan S- 1,25 C- 0,75 X 180 dan power mata kiri S- $0.50 \quad$ C-0.75 X180 menghasilkan 3 hasil jarak baca dekat sebesar $26 \mathrm{~cm}, 27 \mathrm{~cm}, 30 \mathrm{~cm}$. Dan jika tidak menggunakan koreksi maksimal atau (unaided) menghasilkan 3 hasil jarak baca dekat sebesar $17 \mathrm{~cm}, 17 \mathrm{~cm}, 18 \mathrm{~cm}$.

Sampel keempat berjenis kelamin perempuan yang berusia 21 tahun dengan power koreksi maksimal (aided) mata kanan S- 
1,25 C- 0,75 X 60 dan power mata kiri S- 0.75 C-0.75 X80 menghasilkan 3 hasil jarak baca dekat sebesar $26 \mathrm{~cm}, 30 \mathrm{~cm}, 29 \mathrm{~cm}$. Dan jika tidak menggunakan koreksi maksimal atau (unaided) menghasilkan 3 hasil jarak baca dekat sebesar $24 \mathrm{~cm}, 24 \mathrm{~cm}, 24 \mathrm{~cm}$. Sampel kelima atau terakhir berjenis kelamin laki-laki yang berusia 22 tahun dengan power koreksi maksimal (aided) mata kanan S-5.00 C- 0,25 X 90 dan power mata kiri S-4.00 C-0.25 X 90 menghasilkan 3 hasil jarak baca dekat sebesar $44 \mathrm{~cm}, \quad 46 \mathrm{~cm}, \quad 45 \mathrm{~cm}$. Dan jika tidak menggunakan koreksi maksimal atau (unaided) menghasilkan 3 hasil jarak baca dekat sebesar $20 \mathrm{~cm}, 20 \mathrm{~cm}, 20 \mathrm{~cm}$.

Berdasarkan tabel 4.2 diatas diketahui bahwa hasil tes baca dekat dengan menggunakan raf rule, dari tiga kali percobaan tes baca dekat, sampel pertama dengan power koreksi maksimal menghasilkan jarak baca dekat dengan rata-rata jarak sebesar $24,33 \mathrm{~cm}$ atau juga dalam dioptri sejumlah 1,27 D, sampel kedua dengan power koreksi maksimal menghasilkan jarak baca dekat dengan ratarata jarak sebesar $34,33 \mathrm{~cm}$ atau juga dalam dioptri sejumlah 1,84 D, sampel ketiga dengan power koreksi maksimal menghasilkan jarak baca dekat dengan rata-rata jarak sebesar $27,67 \mathrm{~cm}$ atau juga dalam dioptri sejumlah 1,49 D, sampel keempat dengan power koreksi maksimal menghasilkan jarak baca dekat dengan rata-rata jarak sebesar $28,33 \mathrm{~cm}$ atau juga dalam dioptri sejumlah 1,54 D. Hasil sampel ketiga dan keempat menunjukan perbedaan jarak baca, mengapa demikian, karena apabila merujuk pada teori spheris equivalen dimana hasil axis horizontal bisa diakumulasikan menjadi spheris minus, berbeda dengan axis vertical yang tidak bisa di akumulasikan menjadi spheris, maka dari itu dengan kata lain apabila dilakukan spheris equivalen, besaran power sampel ketiga lebih besar dari pada sampel keempat yang mengakibatkan lag akomodasi sampel ketiga lebih dekat. dan sampel kelima atau terakhir dengan power koreksi maksimal menghasilkan jarak baca dekat dengan rata-rata jarak sebesar $45 \mathrm{~cm}$ atau juga dalam dioptric sejumlah 2,22 D.

Dari 5 sampel sete;lah di hitung rata-rata nya dengan menggunakan rumus range akomodasi, pasien diinstruksikan untuk memberitahukan saat objek target mulai kabur saat didekatkan dan kapan kabur kembali saat objek target dijauhkan. Range akomodasi lalu dihitung dengan menentukan titik jauh dan titik dekat dalam dioptri (membagi 100 dengan masing-masing jarak dalam $\mathrm{cm}$ ), lalu kurangi nilai titik jauh dengan titik dekat(sumber). Setelah dihitung dengan range akomodasi, peneliti berhasil mendapatkan hasil, yaitu sampel pertama 0.02 D (dibawah 0.3D / depth of focus), pasien kedua 1.34 D (diatas 0.3D / depth of focus), pasien ketiga 0.24 D (dibawah 0.3D / depth of focus), pasien keempat 0.29 D (dibawah 0.3D / depth of focus), pasien kelima $2.78 \mathrm{D}$ (diatas 0.3D / depth of focus). Dan hasilnya setelah dihitung rata-rata nya kelompok ukuran miopia ringan ada 4 sampel yaitu 1.89D dan kelompok ukuran miopia sedang ada 1 orang yaitu $2,78 \mathrm{D}$, dengan kata lain ada 2 orang yang mengalami kelainan akomodasi, dikarenakan hasilnya tidak sesuai 
dengan revalansi dioptri amplitudo akomodasi.

Besarnya lag of accommodation ini seharusnya tidak melampaui besarnya depth of focus yaitu sebesar \pm 0.3 D. Karena bila itu terjadi retinal defocus tersebut akan mengakibatkan dihasilkannya bayangan yang buram.

\section{KESIMPULAN}

1. Kelanain miopia astigmatis compocitus terhadap baca berdasarkan derajat amplitudo akomodasi adalah 1,89 derajat miopia ringan dan 2,78 derajat miopia sedang

2. Kelainan refraksi miopia astigmatis compocitus terhadap baca dekat berdasarkan jarak baca adalah 28,66 cm dengan derajat miopia ringan, dan $45 \mathrm{~cm}$ dengan derajat miopia sedang

3. Gambaran kelainan refraksi miopia astigmatis compocitus terhadap baca dekat berdasarkan usia dan jenis kelamin. Dengan rata-rata usia remaja yang berumur 20 tahun, dan juga yang berjenis kelamin lakilaki berjumlah 3 orang, 2 diantaranya berakomodasi dengan normal, dan yang berjenis kelamin perempuan berjumlah 2 orang, 1 diantaranya berakomodasi dengan normal

\section{DAFTAR PUSTAKA}

ARIANTI, M. P. (2013). HUBUNGAN ANTARA RIWAYAT MIOPIA DI KELUARGA. PONTIANAK: Universitas Tanjung Pura.

Burns, D. H., Allen, P. M., Edgar, D. F., \& Evans, B. W. (2018). A Review of Depth of Focus in Measurement of the
Amplitude Of Accommodation. mdpi journal vision, 4.

Dinas Kesehatan Jawa Barat dr.H.Dodo Suhendar, M. (2017, Oktober 23). Peringatan Hari Penglihatan Sedunia 2017. Retrieved Januari 30, 2020, from dinkes.jabar:

http://www.diskes.jabarprov.go.id/index.p $\mathrm{hp} /$ post/read/2017/535/Peringatan-HariPenglihatan-Sedunia-2017/g

Fathnur Sani K., M. A. (2018). Metodologo Penelitian Farmasi Komunitas dan Eksperimental. Yogyakarta: deepublish.

Hidayat, A. (2010). Metode Penelitian Kesehatan Paradigma Kuantitatif. Jakarta: Heat Books.

Ilyas, S. (2018). ILMU KESEHATAN MATA. In S. Ilyas, ILMU KESEHATAN MATA (pp. 64-65). Jakarta: FKUI.

Ilyas, S. (2018). ILMU PENYAKIT MATA. Jakarta: Badan Penerbit FKUI.

Ilyas, S., \& Yulianti, S. R. (2011). ILMU PENYAKIT MATA. Jakarta: Badan Penerbit FKUI.

Lukman, F., Lindra, A., \& Heriana. (2016). SKRINING KELAINAN REFRAKSI MATA PADA SISWA SEKOLAH DASAR MENURUT TANDA DAN GEJALA. Semarang.

Meslin, D. (2008). Practical refraction, essilor academy europe. 9 .

Nemeth G, s. E. (2013). Astigmatism Prevalence and Biometric in Normal Population. Europian Jurnal Of Opthalmology.

Notoatmodjo, S. (2018). METOLODOGI PENELITIAN KESEHATAN. Jakarta: PT RINEKA CIPTA.

Rabbett's, R., \& Bennett, A. G. (2016). Clinical Visual Optics.

Radner, W. (2016). Reading charts in ophthalmology. Graefes Arch Clin Exp Ophthalmol, 1468. 
Radner, W. (2017, Maret 22). Reading charts

Sharma, I. P. (2017, Februari 8). RAF near in ophthalmology. Retrieved Februari 3, 2020, from Graefes Arch Clin Exp Ophthalmol:

https://www.ncbi.nlm.nih.gov/pmc/articl es/PMC5541099/pdf/417_2017_Article_ 3659.pdf

Rifati L, R. T. (2013). Kesehatan indera. point rule for near point of convergence. Retrieved Februari 3, 2020, from Department of Ophthalmology, Regional Referral Hospital: http://aes.amegroups.com/article/view/3 639/4374

Wati, R. (2018). Akomodasi dalam Refraksi. Akomodasi dalam Refraksi, 14. 